[0212-7199 (2007) 24: 12; pp. 588-590] ANALES DE MEDICINA INTERNA Copyright (C) 2007 ARAN EDICIONES, S.L.

AN. MED. INTERNA (Madrid) Vol. 24, N. ${ }^{\circ} 12 ;$ pp. 588-590, 2007

\title{
Infiltrado pulmonar y fiebre tras la resolución de neumonía por Pneumocystis jirovecii en un paciente con infección por el VIH
}

\author{
C. CONDE GUZMÁN, R. LUQUE MÁRQUEZ ${ }^{1}$, M. AGUILAR GUISADO ${ }^{1}$ \\ Servicio de Medicina Interna. Hospital General. Ciudad Real. ${ }^{\prime}$ Servicio de Enfermedades \\ Infecciosas. Hospital Universitario Virgen del Rocío. Sevilla
}

PULMONARY INFILTRATES AND FEVER IN A HIV INFECTED PATIENT AFTER PNEUMOCYSTIS JIROVECII PNEUMONIA

\begin{abstract}
RESUMEN
El diagnóstico de enfermedad por citomegalovirus (CMV) en el paciente con infección por VIH no resulta con frecuencia fácil y suele aparecer en el contexto de inmunosupresión severa por reactivación o reinfección del virus. Además, aunque tras la introducción de terapia antirretroviral de gran actividad (TARGA) la incidencia de enfermedad por CMV ha disminuido de forma drástica, es una entidad a tener en cuenta con considerable morbimortalidad. Presentamos el caso de un paciente con fiebre infiltrados pulmonares y dolor abdominal tras la resolución de una neumonía por P.jirovecii con aislamiento de CMV (shellvial positivo) en LBA y biopsia gástrica. Se plantea el posible diagnóstico de enfermedad digestiva y pulmonar por CMV iniciando tratamiento dirigido con respuesta clínica. En este paciente llama la atención la rápida progresión a SIDA desde el diagnóstico y resulta sugerente la hipótesis de que una coinfección simultánea de VIH y CMV fuese la responsable del rápido deterioro inmunológico.
\end{abstract}

PALABRAS CLAVE: Citomegalovirus. VIH. SIDA. Infiltrado pulmonar. Lavado broncoalveolar.

\begin{abstract}
In HIV-infected patients, cytomegalovirus (CMV) disease diagnosis is usually difficult and disease results from reactivation of latent infection or reinfection in the context of severe inmunosupresion. Although the introduction of highly active antiretroviral therapy (HAART) has resulted in a important decline of CMV disease, it has considerable morbidity and mortality rate. We present a case of a patient who presented fever, pulmonary infiltrates and abdominal pain after P.jirovecii pneumonia, with isolated of CMV (positive shell-vial) from LBA and gastric biopsy. We propose a possible diagnosis of digestive and pulmonary $C M V$ disease and we iniciated treatment for this with clinical response. It results surprising the rapid progression to SIDA of the patient and we can suggest that a co-infection HIV-CMV could be the cause for the rapid immunological damage.
\end{abstract}

KEY WORDS: Cytomegalovirus. HIV. AIDS. Shell-vial. Pulmonary infiltrate. Bronchoalveolar lavage.

Conde Guzmán C, Luque Márquez R, Aguilar Guisado M. Infiltrado y fiebre tras la resolución de neumonía por Pneumocystis jirovecii en un paciente con infección por el VIH. An Med Interna (Madrid) 2007; 24: 588-590.

\section{INTRODUCCIÓN}

El diagnóstico de enfermedad por citomegalovirus (CMV) en el paciente con infección por VIH no resulta con frecuencia fácil y suele aparecer en el contexto de inmunosupresión severa por reactivación o reinfección del virus. Además, aunque tras la introducción de terapia antirretroviral de gran actividad (TARGA) la incidencia de enfermedad por CMV ha disminuido de forma drástica, es una entidad a tener en cuenta con considerable morbimortalidad.

\section{CASO APORTADO}

Presentamos el caso de un varón de 23 años diagnosticado de infección por VIH cinco meses antes, vía de transmisión homose- xual. Fue donante de sangre hasta un año atrás confirmándose en el archivo de donantes que la serología VIH previa era negativa. El ELISA para citomegalovirus (CMV) en el momento del diagnóstico era positivo. Un mes antes del ingreso tenía linfocitos $254 \mathrm{CD} 4 / \mu 1$ $(19,2 \%)$ y 1420 copias/ml de carga viral. No recibía terapia antirretroviral (TAR) ni profilaxis para infecciones oportunistas.

Ingresó por insuficiencia respiratoria grave diagnosticándose de neumonía por Pneumocystis jirovecii (PCP) con un cuadro clínicoradiológico compatible (Fig. 1) y el aislamiento de quistes en esputo. Se inició tratamiento con cotrimoxazol $(20 / 100 \mathrm{mg} / \mathrm{kg} /$ día i.v.) y metilprednisolona ( $40 \mathrm{mg} / 12 \mathrm{~h}$ i.v.) y la evolución clínica fue favorable con resolución completa del infiltrado intersticial. El día $7^{\circ}$ de ingreso se inició TAR con didanosina $400 \mathrm{mg} /$ día, lamivudina 300 $\mathrm{mg}$ /día y saquinavir $1500 \mathrm{mg}$ /día potenciado con ritonavir 100 $\mathrm{mg}$ /día, con buena tolerancia y sin aparición de efectos secundarios.

El día $22^{\circ}$ de ingreso, tras reducir cotrimoxazol a dosis profilácticas $\left(160 / 600 \mathrm{mg} /\right.$ día vo), comenzó con fiebre elevada $\left(39^{\circ} \mathrm{C}\right)$, dolor

Trabajo aceptado: 16 de julio de 2007

Correspondencia: Concepción Conde Guzmán. Servicio de Medicina Interna. Hospital General de Ciudad Real. C/ Tomelloso, s/n. 13005 Ciudad Real. e-mail: conedo99@hotmail.com 


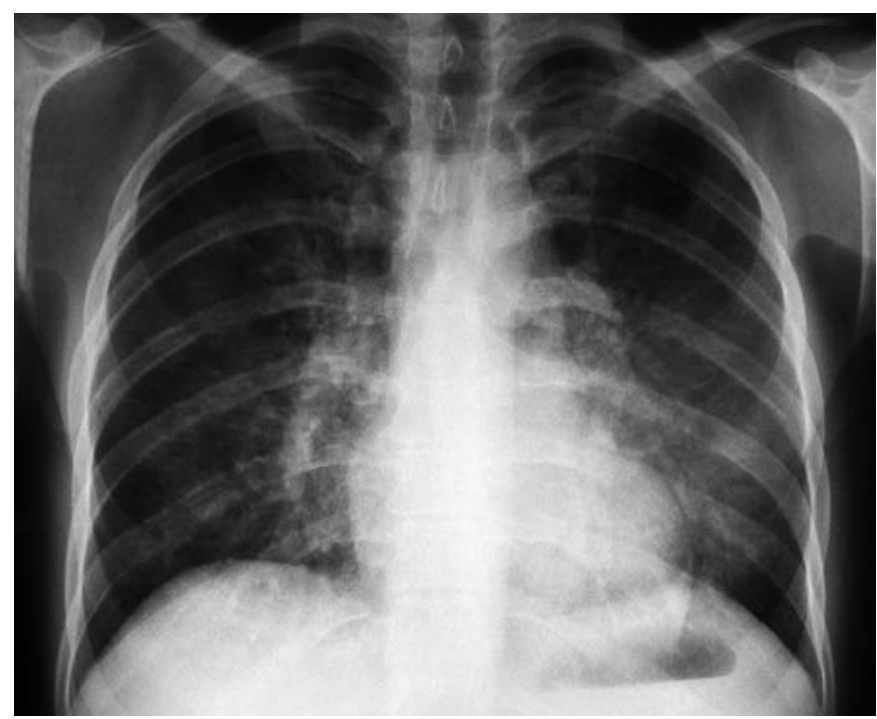

Fig. 1. Infiltrado intersticial bilateral.

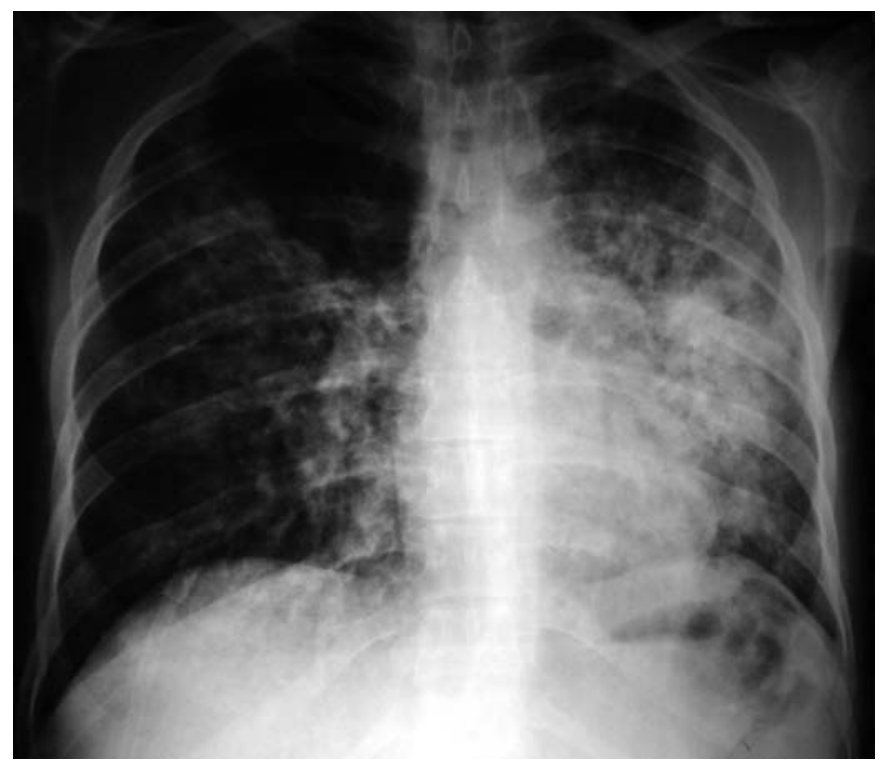

Fig. 2. Infiltrado alveolar LSI y LMD.

sordo y continuo en epigastrio, y 3-4 deposiciones diarreicas diarias sin productos patológicos. Cuatro días más tarde presentó tos seca y disnea progresiva apreciándose un infiltrado alveolar bilateral que afectaba a casi todo el pulmón izquierdo y al lóbulo superior derecho (Fig. 2).

A la exploración el paciente estaba febril $\left(38^{\prime} 3^{\circ} \mathrm{C}\right)$ con afectación del estado general y aumento del trabajo respiratorio (frecuencia respiratoria $32 \mathrm{rpm}$ y saturación basal de $\mathrm{O}_{2} 84 \%$ ). Se objetivó dolor a la palpación en epigastrio, siendo el resto de la exploración incluido el fondo de ojo, normal.

Nos planteamos el siguiente diagnóstico diferencial: a) neumonía nosocomial (fundamentalmente por Pseudomonas spp., Legionella spp. y neumococo); b) recidiva de neumonía por $P$. Jirovecii; c) infección por otros oportunistas con afectación pulmonar y/o digestiva como CMV, Micobacterium tuberculosis o Micobacterium avium-intracellulare; y d) síndrome de reconstitución inmune por la relación temporal con el inicio de TAR y la suspensión de corticoides (una semana antes). Se inició tratamiento empírico con cefepime ( $2 \mathrm{gr} / 8 \mathrm{~h}$ i.v.), levofloxacino (500 mg/24h i.v.), ganciclovir ( $5 \mathrm{mg} / \mathrm{kg} / 12 \mathrm{~h}$ i.v.) y cotrimoxazol a dosis terapéuticas. En las determinaciones analíticas destacaban: 9450 leucocitos/ $\mu$ l (82 neutrófilos, $15 \%$ linfocitos), $\mathrm{LDH}$ $1.160 \mathrm{UI} / \mathrm{l}$, PCR 89,1 mg/l, VSG $68 \mathrm{~mm} / \mathrm{h}, 166 \mathrm{CD} 4 / \mu \mathrm{l}(16,6 \%)$ у 361.000 copias $/ \mathrm{ml}$ de carga viral. La antigenemia CMV en dos determinaciones de días diferentes fue de 12 y 19 leuc/100.000. Los hemocultivos, coprocultivos y la antigenuria a neumococo y Legionella pneumophila fueron negativos. La tomografía computerizada de tórax y abdomen mostraba un infiltrado pulmonar en "vidrio deslustrado" que ocupaba el segmento anterior de LSD y LMD y prácticamente todos los lóbulos del pulmón izquierdo. Se realizó una endoscopia digestiva alta que mostraba una gastritis erosiva antral inespecífica aunque el shell-vial para CMV de la biopsia gástrica fue positivo. La fibrobroncoscopia no mostraba alteraciones en el árbol bronquial. En el lavado broncoalveolar (LBA) la baciloscopia, el cultivo de Lowenstein, la tinción para $P$. Jirovecii y la citología fueron negativos, sin embargo el shell-vial para CMV fue positivo.

Tras recibir los resultados de las pruebas complementarias se continuó con ganciclovir intravenoso y cotrimoxazol a dosis profilácticas suspendiendo el resto del tratamiento. La evolución fue favorable con desaparición de la fiebre y la sintomatología digestiva. Completó tratamiento 21 días con valganciclovir (900 mg/12 h v.o.). En el seguimiento en consultas externas un mes después continuaba asintomático.

Diagnóstico: posible enfermedad por citomegalovirus con afectación pulmonar y digestiva. Neumonía por P. Jirovecii. Infección por el VIH categoría C3.

\section{DISCUSIÓN}

Tras la introducción de terapia antirretroviral de gran actividad (TARGA) la incidencia de enfermedad por CMV ha disminuido de forma drástica paralelamente a la de otras infecciones oportunistas definitorias de SIDA (1-3). En pacientes infectados por VIH, la enfermedad por CMV generalmente ocurre por reactivación de infección latente en el contexto de una inmunosupresión severa aunque puede ocurrir durante la primoinfección o reinfección por este virus (3).

El diagnóstico de enfermedad por $\mathrm{CMV}$ en el paciente infectado por VIH es con frecuencia difícil. En homosexuales se han observado tasas de coinfección VIH-CMV de hasta un $90 \%$ y cuando su estadío inmunológico se deteriora es frecuente encontrar datos de presencia viral en sangre y otras secreciones sin evidencia de enfermedad (4). Clínicamente la enfermedad por CMV es a veces indistinguible de los síndromes producidos por otros patógenos, exceptuando quizás la retinitis (2). La detección de viremia por CMV determinada por antigenemia pp65 o reacción en cadena de la polimerasa (PCR) tiene un elevado valor predictivo de enfermedad por CMV en pacientes con SIDA $(1,3)$. Sin embargo es necesario demostrar el efecto citopático del virus, mediante la visualización de los cuerpos de inclusión intranucleares para confirmar el diagnóstico de enfermedad (2).

En concreto la afectación pulmonar tiene dificultades añadidas al diagnóstico ya que el aislamiento en LBA no diferencia la infección asintomática de la neumonitis, es frecuente la coexistencia con otros patógenos y el patrón radiológico no es específico $(2,5)$. Tampoco existe clara relación entre el cultivo de CMV en sangre y en LBA (6). En algunas series se ha aislado CMV en LBA hasta en el $50 \%$ de los casos que se diagnostican por primera vez de PCP y este aislamiento no guarda relación con la evolución de la misma, por lo que inicialmente 
no se recomienda tratamiento para CMV (5). En estos casos la presencia de enfermedad extrapulmonar, la severa inmunosupresión y la aparición de nuevos infiltrados en la radiografía de tórax son factores predictivos independientes de neumonía por CMV (7).

En nuestro paciente aunque no disponemos de certeza diagnóstica, se asumió la posible infección diseminada por CMV en base a la clínica, la detección de antigenemia de

\section{Bibliografía}

1. Pozamczer D, Arribas JR, Mallolas J, Peña JM, Pulido F, et al. Recomendaciones del grupo de estudio del Sida (GESIDA). Tratamiento de las infecciones oportunistas en pacientes adultos y adolescentes infectados por el virus de la inmunodeficiencia humana en la era del tratamiento antirretrovírico de gran eficacia. Enferm Infecc Microbiol Clin 2001; 19: 376-392.

2. Whitley RJ, Jacobson MA, Friedberg DN, Holland GN, Jabs DA, Dieterich DT, et al. Guidelines for the treatment of Cytomegalovirus diseases in patients with AIDS in the era of potent antiretroviral therapy. Arch Inter Med 1998; 158: 957-69.

3. Deayton JR. Changing trends in Cytomegalovirus disease in HIV-infec-
CMV, la detección del CMV en el LBA y biopsia gástrica en ausencia de otro patógeno oportunista y la buena respuesta al tratamiento antiviral exclusivo aunque ocurrió sin inmunodepresión severa.

Sorprende en este caso la rápida progresión a SIDA desde la fecha de infección. Podría plantearse que una coinfección simultánea de VIH y CMV estuviese en relación con el rápido deterioro inmunológico. ted patients. HERPES 2001; 8: 37-41.

4. Collier AC, Meyers JD, Corey L. Cytomegalovirus infection in homosexual men. Am J Med 1987; 82: 493-500.

5. Rodríguez-Barradas MC, Stool E, Musher DM, Gathe J, Goldstein J, Genta RM, et al. Diagnosing and treating Cytomegalovirus pneumonia in patients with AIDS. CID 1996; 23: 76-81.

6. Miles PR, Baughman RP, Linnenann CC. Cytomegalovirus in LBA of patients with AIDS. Chest 1990; 97: 1072-6.

7. Salomón N, Gómez T, Perlman DC, Laya L, Eber C, Mildvan D, et al Clinical features and outcome of HIV-related cytomegalovirus pneumonia. AIDS 1997; 11: 319-24 